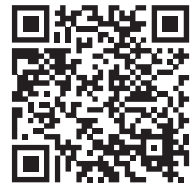

Enero - Marzo 2022 Vol. 2, núm. 1 / pp. 12-18
Palabras clave: Protocolos, Unidades de Cuidados

Intensivos, salud

bucal, neumonía asociada al ventilador.

Keywords:

Protocols, Intensive

Care Units, oral

health, ventilatorassociated pneumonia.
* Cirujano Maxilofacial. Editor de la revista de la Asociación Latinoamericana de Cirugía Bucomaxilofacial (CBMF), Certificado por ALACIBU BOARD. Presidente del

Comité de Ética e Investigación de Santa Paula. Miembro Asociado de la Asociación Europea de Cirugía Maxilofacial. Preceptor externo de la Residencia de Neurocirugía del Hospital Santa Paula. Brasil.

₹ Doctora de Enfermedades Infecciosas. Doctora en

Ciencias por la Facultad de Medicina de la Universidad de São Paulo. Brasil.

$\S$ Cirujana Dentista egresada de la Universidad Metodista de

Recibido: 28/09/2021 Aceptado: 14/10/2021

doi: $10.35366 / 103404$

\section{Protocolo y atención de infecciones bucales en pacientes COVID-19}

\author{
Protocol and care of oral infections in COVID-19 patients
}

Luiz Fernando Lobo, ${ }^{\star}$ Cristhieni Rodrigues, ${ }^{\ddagger}$ Laura Trench Pinto, $§$ Ana Tarina Lopes $\rrbracket$

\section{RESUMEN}

Este trabajo es un reporte de series de casos que tiene como objetivo proponer y revisar un protocolo para la atención de infecciones pulmonares y lesiones en la cavidad oral en pacientes con COVID-19 ingresados en la Unidad de Cuidados Intensivos (UCI) del Hospital Santa Paula. En una revisión de la literatura queda clara la importancia de la salud bucal para estos pacientes ingresados en la $\mathrm{UCl}$. Para ello, se estableció un protocolo de atención y se evaluó a los pacientes diariamente. Los datos se ingresaron en una hoja de cálculo de recopilación de datos. Los resultados mostraron que hubo una mejora en la calidad de la higiene bucal, mejor hidratación y, en consecuencia, una mejora en la evolución clínica de las lesiones bucales. Concluimos que el papel de un equipo multidisciplinario en la atención de los pacientes hospitalizados con COVID-19 ayuda en la calidad de vida, agiliza la recuperación y previene más complicaciones.

\section{ABSTRACT}

This work is a report of a series of cases that aims to propose and review a protocol for the care of lung infections and injuries in the oral cavity in patients with COVID-19 admitted to the ICU of Hospital Santa Paula. In a review of the literature, the importance of oral health for these patients admitted to the ICU, especially SARS$\mathrm{CoV}-2$, is clear. For this, a care protocol was established, and the patients were evaluated daily. The data was entered into a data collection spreadsheet. The results showed that there was an improvement in the quality of oral hygiene, better hydration and, consequently, an improvement in the clinical evolution of oral lesions. We conclude that the role of a multidisciplinary team in the care of hospitalized patients with COVID-19 helps in their quality of life, speeds up recovery and prevents further complications.

\section{ReVISIÓN DE LITERATURA}

Se sabe que los pacientes ingresados en la Unidad de Cuidados Intensivos ( $\mathrm{UCl}$ ) requieren una higiene frecuente de la cavidad oral debido a su exposición al ambiente hospitalario contaminado, especialmente los asociados a la ventilación mecánica (VA). En busca de mejoras en la atención de la higiene bucal de los pacientes hospitalizados se crearon protocolos específicos para facilitar las acciones y brindar atención a estos pacientes. ${ }^{1-3}$

Los cambios en la flora oral, el $\mathrm{pH}$ de la saliva y los traumatismos menores de la mucosa pueden ocasionar desequilibrio de la flora y contribuir a la neumonía bacteriana. Esta crisis de salud desde el punto de vista del SARS-CoV-2 nos llevó a la necesidad de desarrollar protocolos de atención para cubrir las demandas y variables cada vez más agudas y las complicaciones que se presentan. Una de las complicaciones es la neumonía bacteriana. Se sabe que la cavidad bucal alberga una flora bacteriana y fúngica muy variada y que el equilibrio se basa en factores metabólicos y hormonales. Una patología como ésta que induce a inmunosupresión significativa, xerostomía y cambio en la ventilación puede ocasionar un cambio en la flora bucal, lo que propicia el crecimiento de bacterias oportunistas o incluso hongos que causan complicaciones. ${ }^{4,5}$

La mala higiene bucal es común en los pacientes de la $\mathrm{UCl}$, lo que ocasiona la colonización del biofilm oral por microorganismos patógenos, especialmente patógenos respiratorios. Los estudios muestran claramente que la cantidad de biofilm oral en pacientes de la $\mathrm{UCl}$ aumenta con el tiempo. ${ }^{6,7}$ 
São Paulo. Miembro del equipo de Cirugía y Traumatología Maxilofacia del Hospital Santa Paula. Brasil. "Coordinadora del Centro de Investigaciones Clínicas del Hospital Santa Paula. Coordinadora del CRF-SP Clinical Research GTT. Brasil.
La asistencia sanitaria en el ámbito hospitalario requiere de un equipo multidisciplinario. Este hecho exigió la introducción de la odontología en este entorno laboral. El odontólogo que labora en las Unidades de Cuidados Intensivos debe estar preparado para la atención odontológica en condiciones específicas y diferenciadas del consultorio. ${ }^{8,9}$

La mala salud oral puede conllevar problemas clínicos, como la propagación local de infecciones de origen oral, que pueden derivar en infecciones del tracto respiratorio, mayores costos de ingreso a la UCl y mayor uso de fármacos como antibióticos, lo que propicia el establecimiento de bacterias, resistencia y otras infecciones oportunistas..$^{8,10}$

La neumonía nosocomial se considera la segunda infección hospitalaria más común y la causa más frecuente de muerte entre las infecciones adquiridas en el hospital, siendo más común en pacientes intubados y ventilados mecánicamente. ${ }^{3,11-13}$

Ante los riesgos bacterianos derivados de la cavidad oral se refuerza la importancia de la limpieza completa de sus tejidos y la evaluación de un cirujano dentista. ${ }^{14,15}$

Se realizó una encuesta a 213 pacientes para verificar si la higiene oral mediante cepillado de dientes y gel de clorhexidina al $0.12 \%$ reduce la incidencia de neumonía asociada al ventilador, el tiempo de ventilación mecánica, la estancia hospitalaria y la tasa de mortalidad en la UCI en comparación con la higiene oral con sólo clorhexidina al $0.12 \%$ en solución, sin cepillar, en pacientes adultos. El cepillado de dientes asociado con gel de clorhexidina al $0.12 \%$ demostró menor incidencia de neumonía asociada a la ventilación (NAV) durante el periodo de seguimiento, aunque la diferencia no fue estadísticamente significativa. Hubo una reducción significativa en la duración media de la ventilación mecánica en el grupo de cepillado. ${ }^{16,17}$

Objetivo: a partir de un protocolo propuesto por el grupo de atención COVID-19 se creó un protocolo de atención. El objetivo de este estudio es obtener datos y generar evidencia, en consecuencia, crear protocolos para realizar la higiene oral en pacientes con sospecha y confirmación de COVID-19 con el fin de prevenir neumonía (protocolo de asistencia).

\section{Material y métodos}

Este estudio se realizó en la UCI del Hospital Santa Paula, junto con todo el equipo de mé- dicos y auxiliares clínicos. Todos los pacientes ingresados en la UCl del Hospital Santa Paula fueron observados en sus condiciones orales y sometidos al protocolo COVID. Estos datos se observaron diariamente (D15) desde el 01 de abril hasta el 15 de abril de 2021, se anotaron y comentaron en tablas y se coordinaron acciones junto con el equipo del centro de investigación. ${ }^{18,19}$

\section{Protocolo}

1. Para el proceso de servicio se estableció:

a. Todo el equipo de protección personal (EPP) debe colocarse previo al ingreso a la habitación (protocolo propuesto por la AIMB-Higiene Oral). 3,20,21 Precauciones para aerosoles y contacto.

b. Máscara y protector facial N95.

2. Pacientes sometidos a ventilación mecánica o traqueotomía:

a. Hisopos orales o de gasa empapados en $15 \mathrm{~mL}$ de peróxido de hidrógeno al $1 \%$ o yodopovidona al $0.2 \%$ durante un minuto, dos veces.

b. Higiene bucal con clorhexidina al $0.12 \%$ cada 12 horas.

c. Aplicar vitamina E en la mucosa oral.

d. Casos que presentan ulceraciones. d.1. Láser.

e. En los casos en los que se identifique la presencia de Candida.

e.1. Nistatina.

f. Pacientes con ventilación espontánea.

f.1. Según un estudio publicado en la edición de octubre de 2006 de la Revista Brasileña de Terapia Intensiva, la acumulación de placa dental y la colonización de la región orofaríngea por bacterias y patógenos está directamente asociada con la aparición de neumonía nosocomial causada por la ventilación mecánica.

f.2. En pacientes conscientes orientados: guiar la realización de la higiene oral con cepillo y pasta de dientes al amanecer, después de las comidas y siempre que sea necesario. Recomendar un enjuague bucal con 15 $\mathrm{mL}$ de peróxido de hidrógeno al $1 \%$, uno por día, cepillando los dientes en secuencia. 


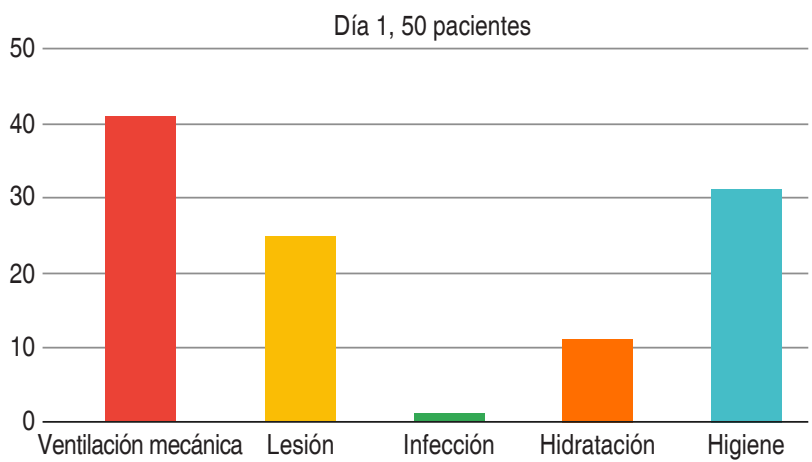

Figura 1: Valoración del paciente el día 1.

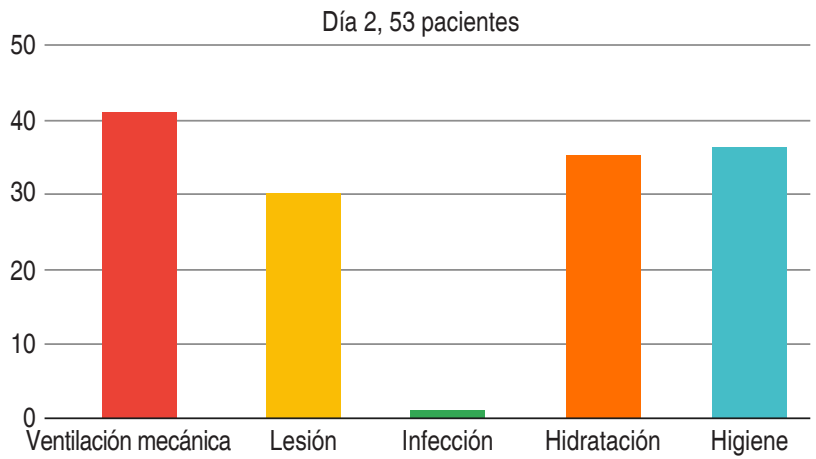

Figura 2: Valoración del paciente el día 2.

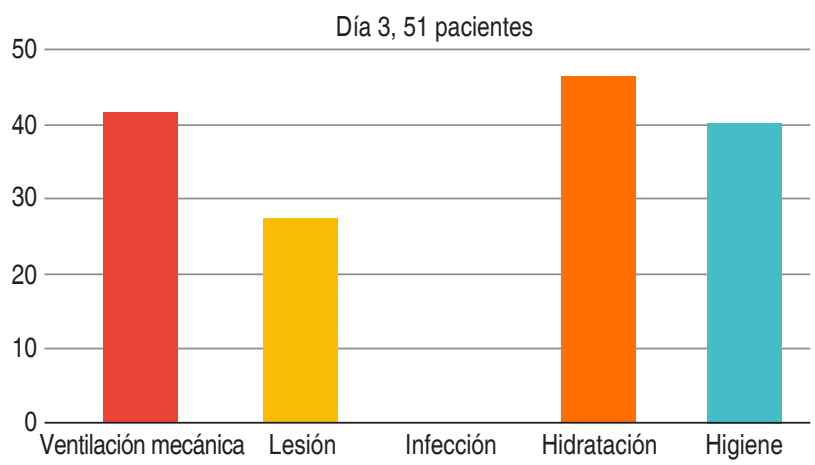

Figura 3: Valoración del paciente el día 3.

\section{Resultados}

Todos los datos son ingresados en una hoja de cálculo y discutidos por el grupo para validar las acciones.

Las figuras 1 a 14 describen la alta frecuencia de lesiones encontradas tales como úlceras traumáticas causadas por compresión del tubo, o úlceras por resequedad, periodontitis, resequedad labial, candidiasis, entre otras. Se consideran como lesiones la presencia o ausencia de foco infeccioso, si hubo o no hidratación en labios y mucosas y si se realizó o no una adecuada higiene oral.

Las figuras 1 a 14 muestran la rutina que se implementó, así como lo que se puede observar clínicamente sobre las condiciones encontradas y la respuesta al protocolo.

De esta forma, dentro del plazo de 15 días establecido para obtener los datos de observación podremos registrar y analizar los resultados diarios y ajustar nuestra conducta.

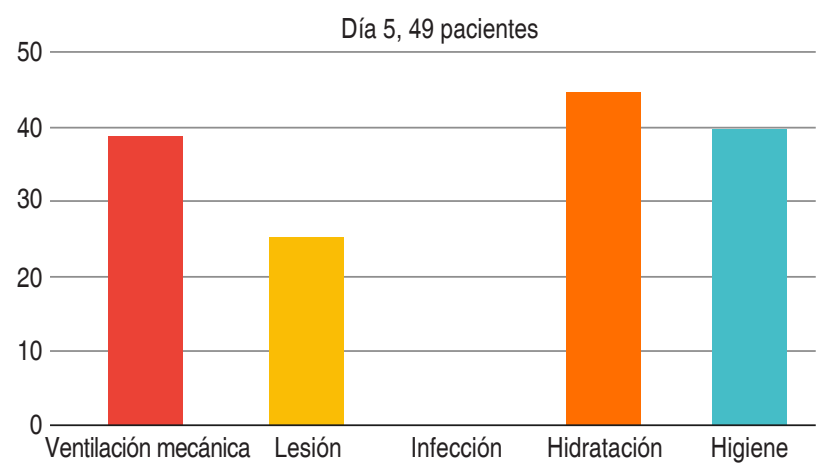

Figura 4: Valoración del paciente el día 4.

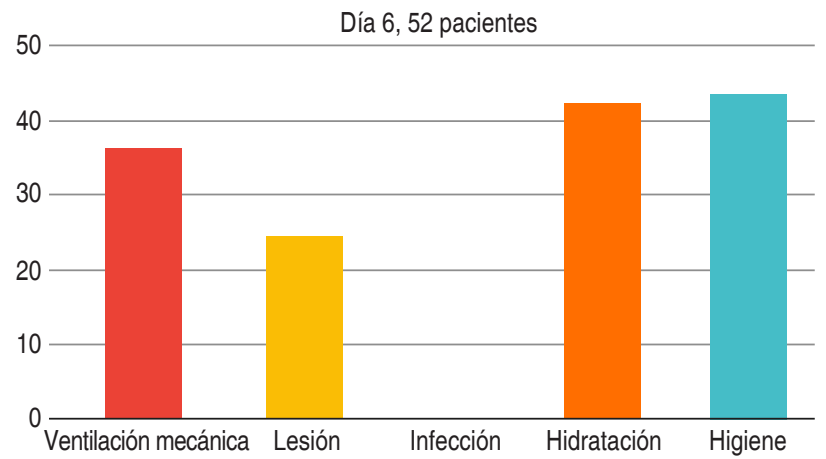

Figura 5: Valoración del paciente el día 6.

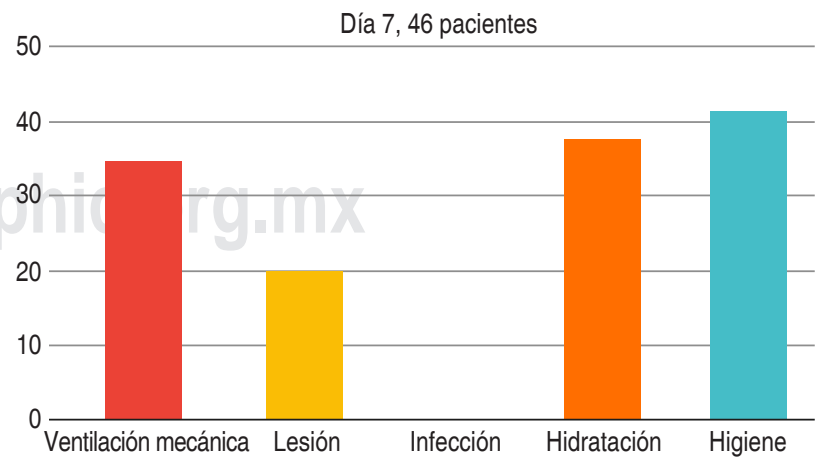

Figura 6: Valoración del paciente el día 7. 


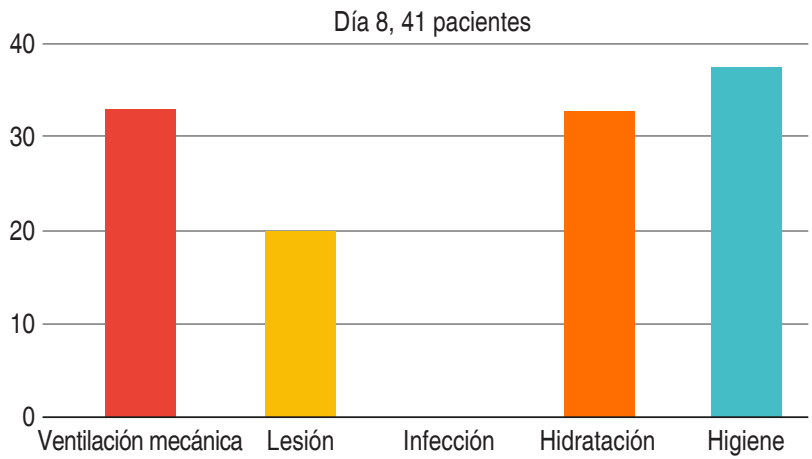

Figura 7: Valoración del paciente el día 8.

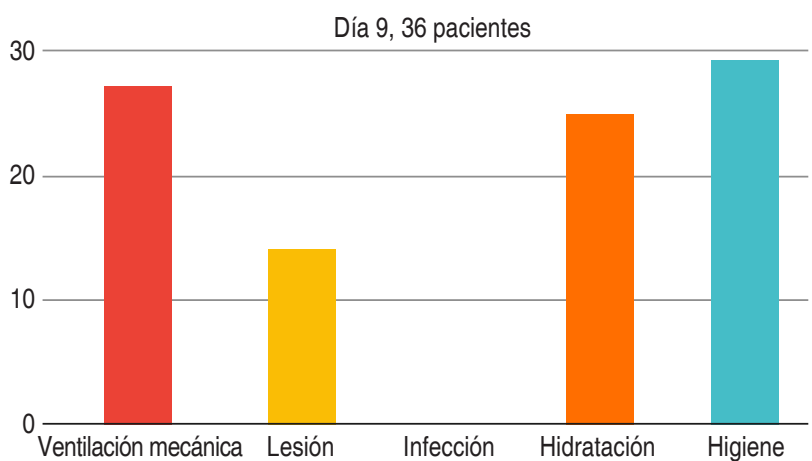

Figura 8: Valoración del paciente el día 9.

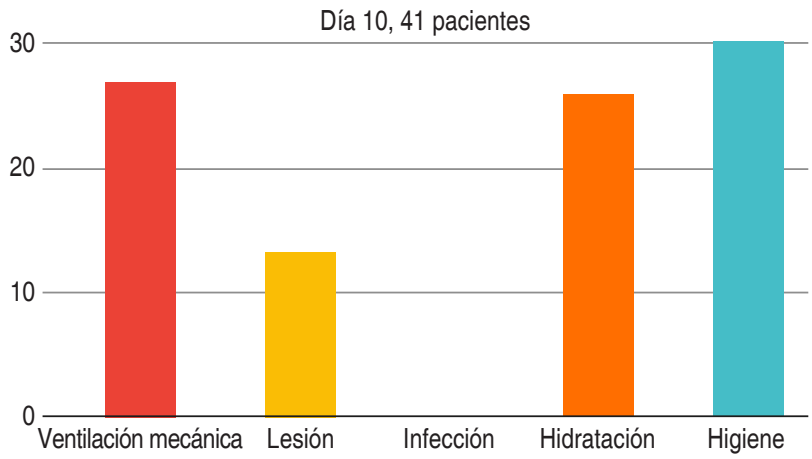

Figura 9: Valoración del paciente el día 10.

Al final podemos observar en cada uno la vigencia del protocolo establecido, lo que nos lleva a mantener la conducta asistencial.

\section{DisCusıón}

Con los objetivos planteados para la atención de infecciones orales en pacientes hospitalizados en la UCI por COVID-19 se propuso un protocolo de atención para infecciones pulmonares y lesiones en la cavidad oral.
Cuando comenzamos el proyecto estábamos en el auge de la segunda ola. La ciudad de São Paulo rompía récord con 75,000 muertes desde el inicio de la pandemia, y con 890 muertes al día. Fue en este ámbito que implementamos el protocolo con la finalidad de mejorar la calidad de vida de los pacientes internados en la $\mathrm{UCl}$.

La literatura que demuestra la importancia de la salud oral para los pacientes ingresados en la $\mathrm{UCl}$ es amplia y podemos asociar esta atención especialmente con los pacientes afectados por SARS-CoV-2.

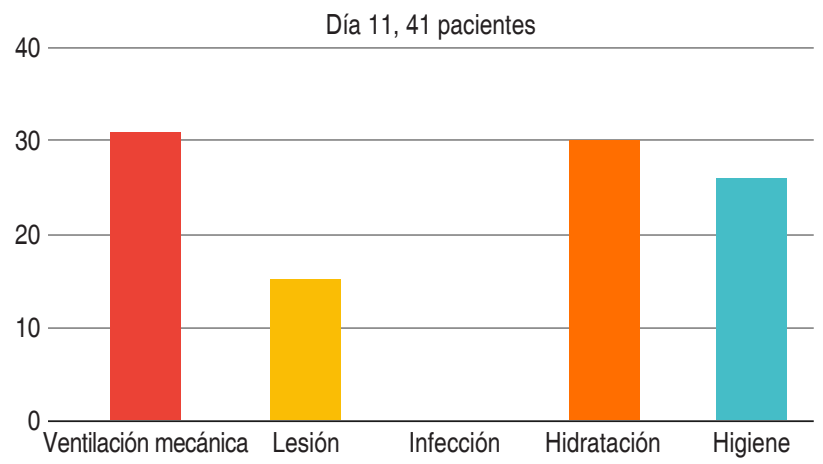

Figura 10: Valoración del paciente el día 11.

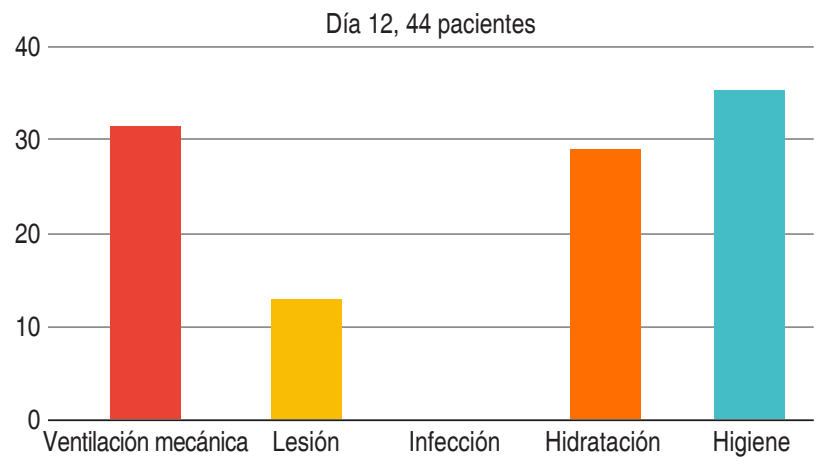

Figura 11: Valoración del paciente el día 12.

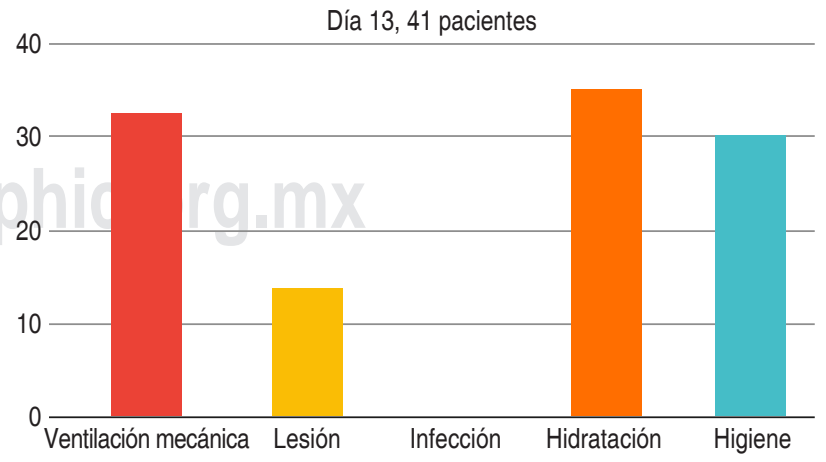

Figura 12: Valoración del paciente el día 13. 


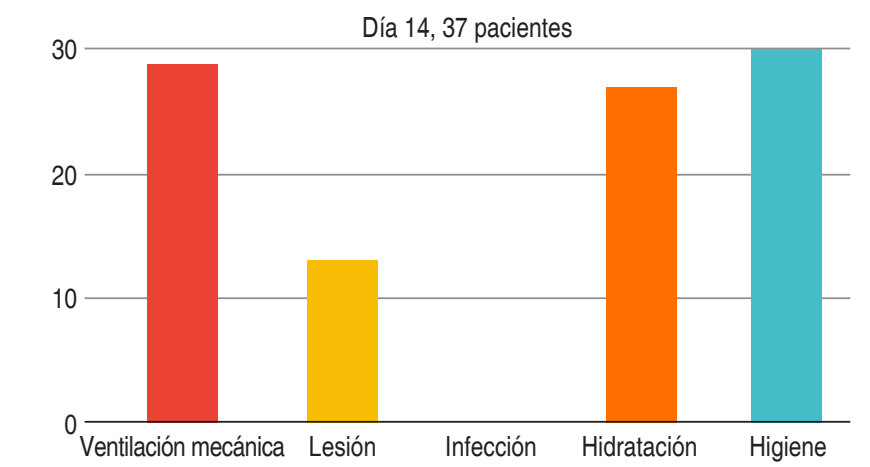

Figura 13: Valoración del paciente el día 14.

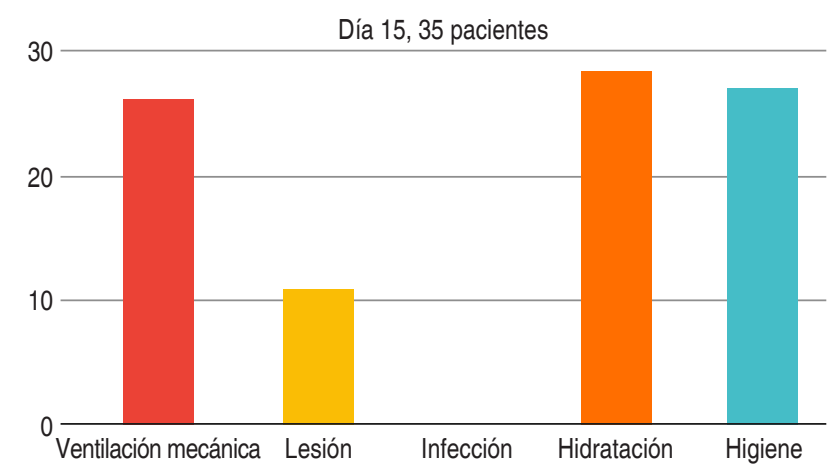

Figura 14: Valoración del paciente el día 15.

Las bacterias grampositivas a menudo constituyen la microflora oral de individuos sanos. Sin embargo, el equilibrio de la microbiota oral de los pacientes hospitalizados en la $\mathrm{UCI}$ durante más de 48 horas tiende a cambiar. Los cambios en la flora oral, el pH de la saliva y los traumatismos menores de la mucosa pueden provocar desequilibrio de la flora y como consecuencia neumonía.

Estas alteraciones dan lugar a una prevalencia de bacterias gramnegativas como Staphylococcus aureus, Streptococcus pneumoniae, Acinetobacter baumannii, Haemophilus influenzae y Pseudomonas aeruginosa.

Este cambio en la patología viral estableció la necesidad de comprender todo el curso y sus manifestaciones. Esto implicó formar grupos de estudio de varios especialistas para comprender mejor y poder controlar la forma aguda de estas alteraciones.

Una de las complicaciones fue la neumonía bacteriana que podemos observar durante las hospitalizaciones. Las diversas bacterias ya descritas se han asociado con la neumonía nosocomial. La propuesta de definir un protocolo de atención fue reducir esta complicación, la cual ya se muestra en este proyecto para atender algunos aspectos.

Para ello, el equipo de Cirugía y Traumatología Maxilofacial del Hospital Santa Paula realizó una selección de los pacientes hospitalizados en la UCl afectados por COVID-19 durante 15 días. Se observó la calidad de la higiene oral, presencia o ausencia de lesiones ulcerativas, hidratación de labios y mucosa oral y manifestaciones derivadas de procesos infecciosos.

Todos los profesionales involucrados en el proyecto durante las evaluaciones usaron EPP completo provisto en un hospital privado, mascarilla N95/PFF-2, careta, bata desechable e impermeable que se cambió para cada paciente y guantes de procedimiento.

En el ámbito de las lesiones ulcerativas destacamos dos causas principales: la compresión o la resequedad que pueden estar asociadas en algunos casos. La compresión del tubo por intubación orotraqueal estuvo presente en algunos casos, lo cual generó dudas sobre la posición fija del tubo. Hablamos con el equipo multidisciplinario para cambiar esta posición todos los días, permitiendo así una mejor higiene bucal y evitar ulceraciones.

Se encontraron pocos casos de lesiones características de candidiasis durante los primeros días de selección, después de tratados y una vez establecido el protocolo de prevención no hubo más casos.

Se instruyó al equipo de enfermería sobre higiene oral. Con la ayuda de una gasa empapada en cloruro de cetilpiridinio $\left(\right.$ Cepacol ${ }^{\circledR}, \sin$ alcohol), dicha higiene se realizó en movimientos delicados posteroanteriores utilizando una gasa para cada hemiarcada y cambiándola en cada una. Se prestó atención a la lengua y al fondo del vestíbulo. En los pacientes con lesiones ulceradas se requirió mayor cuidado durante la limpieza, ya que en algunos casos se presentaba sangrado por fricción de la gasa.

Durante las evaluaciones diarias nos encontramos con una gran rotación de pacientes, considerando casos graves, traslados hospitalarios, muertes, altas hospitalarias hasta pacientes con máscara de alto flujo en posición de prona o en decúbito prono, lo que impedía realizar la evaluación, siendo ésta una de las razones de la variación diaria en los pacientes observados.

Iniciamos las evaluaciones con $82 \%$ de los pacientes utilizando ventilación mecánica (VM), de los evaluados, 50\% presentaba lesiones en la cavidad oral, $2 \%$ mostraba focos infecciosos intraorales, específicamente candidiasis, 22\% tenía buena higiene y sólo $62 \%$ tenía labios hidratados.

La primera semana fue la fase de evaluación primaria de la $\mathrm{UCl}$ con el objetivo de observar los principales problemas, el número de pacientes y la rutina para poder formular el mejor protocolo que cubriera las necesidades que se presentaban. Los gráficos nos muestran que desde el primer día hasta el quinto día de evaluación hubo una caída de $4 \%$ en los pacientes con VM, de 1\% en los pacientes con lesiones en la cavidad oral, y de $2 \%$ de las infecciones; además de un aumento de $68 \%$ en la calidad de la higiene bucal y de $18 \%$ en el índice de hidratación labial.

Del quinto al décimo día de evaluación observamos una diferencia en porcentajes. Fue la semana con más muertes en 
la $\mathrm{UCl}$, lo que dificultó la aplicación del protocolo y repercutió en los resultados. Detectamos una caída de $12 \%$ en pacientes con VM y de $17 \%$ en pacientes con lesiones en la cavidad oral, el porcentaje de pacientes con focos infecciosos fue cero; sin embargo, detectamos una caída de $25 \%$ en la calidad de la higiene y de $6 \%$ en la hidratación labial.

Del décimo al decimoquinto día se observó una estabilización del protocolo orientado a instruir al equipo de enfermería sobre las nuevas medidas adoptadas. Detectamos un descenso de $6 \%$ de pacientes en VM, de $-3 \%$ de pacientes con lesiones y el porcentaje de focos infecciosos se mantuvo en cero, la calidad de la higiene oral aumentó en $17 \%$ y la hidratación labial en 4\%.

Al decimoquinto día, último día de evaluaciones, observamos que de los pacientes ingresados en la UCI COVID, 71\% usaba VM; de los pacientes evaluados, 31\% presentaba lesiones, ningún paciente mostraba foco infeccioso, $80 \%$ de los pacientes tenía buena higiene bucal y $77 \%$ buena hidratación labial.

Hubo una mejoría de las lesiones a medida que aumentaba la hidratación en labios y mucosas junto con las medidas de posicionamiento del tubo de intubación. Además, apreciamos una mejora en la calidad de la higiene oral con una adecuada orientación y trabajo en equipo. Igualmente, se observó un mayor control de las lesiones infecciosas oportunistas.

\section{Conclusión}

1. Con el cambio del $\mathrm{pH}$ oral se produce un desequilibrio de la flora, lo que propicia el crecimiento y cambio selectivo de una nueva flora.

2. Con esto hay menor protección del epitelio de la mucosa oral, lo que puede provocar infecciones oportunistas (fúngicas) o ulcerativas.

a. Una observación importante es que el uso de clorhexidina al $0.12 \%$ puede estar relacionado con posibles efectos secundarios o efectos adversos bien guiados y seguidos de beneficios por un tiempo limitado.

b. Hay controversia en la literatura sobre la cantidad de veces que debe utilizarse. En este caso usamos el patrón indicado por la evidencia en uso en la UCl en COVID. ${ }^{22,23}$

3. En caso de comprobar un aumento del pH y para incrementar la protección de mucosas, y en casos seleccionados según el tiempo y la gravedad, aplicar láser y/o nistatina.

4. Los resultados reportados y demostrados nos autorizan a seguir este modelo de atención.

\section{AgradeCimiento}

Para llevar a cabo este trabajo fue necesario componer un equipo altamente calificado y dedicado. Los doctores Gustavo Passos de F. Lins, Dreyson Motta Nicotari, Maria Julia Valentini Francisco, Leandro Ribeiro de Castro y Lucas Alves Dantas evaluaron diariamente a todos los pacientes en todos los detalles clínicos y los registraron en la historia clínica.

\section{Referencias}

1. Reis de Andrade DS, Freire Cordeiro D, Resende da Costa Santos JR. A relevancia da avaliacao dos protocolos de higiene bucal em pacientes nas uti's: revisao de literatura. Brasil: Universidade Tiradentes; 2019. Disponible en: http://openrit.grupotiradentes.com:8080/xmlui/ handle/set/2394

2. Gomes SF, Esteves MCL. Atuacao do cirurgiao-dentista na UTI: um novo paradigma. Rev Bras Odontol. 2012; 69 (1): 67-70.

3. Recomendacoes - AMIB [Internet]. Org.br. [citado el 15 de septiembre de 2021]. Disponible en: https://www.amib.org.br/informacao/ recomendacoes

4. Ames NJ, Sulima P, Yates JM, McCullagh L, Gollins SL, Soeken K et al. Effects of systematic oral care in critically ill patients: a multicenter study. Am J Crit Care. 2011; 20 (5): e103-e114.

5. Carvajal C, Pobo A, Díaz E, Lisboa T, Llauradó M, Rello J. Higiene oral con clorhexidina para la prevención de neumonía en pacientes intubados: revisión sistemática de ensayos clínicos aleatorizados. Med Clin (Barc). 2010; 135 (11): 491-497.

6. Pegoraro J, Silvestri L, Cara G, Stefenon L, Mozzini CB. Efeitos adversos do gluconato de clorexidina a 0,12\%. J Oral Invest. 2015; 3 (1): 33-37.

7. Oronsky B, Goyal S, Kim MM, Cabrales P, Lybeck M, Caroen S, et al. A review of clinical radioprotection and chemoprotection for oral mucositis. Transl Oncol. 2018; 11 (3): 771-778.

8. Celik GG, Eser I. Exame da saúde bucal dos pacientes da unidade de terapia intensiva. Int J Nurs Pract. 2017; 23 (6): e12592.

9. Guimaraes GR, Queiroz APG, Ferreira ACR. Instituicao de um protocolo de higiene bucal em pacientes internados no CTI do HUSF. Braz J Periodontol. 2017; 27: 7-10.

10. Saunders DP, Epstein JB, Elad S, Allemano J, Bossi P, van de Wetering $M D$, et al. Systematic review of antimicrobials, mucosal coating agents, anesthetics, and analgesics for the management of oral mucositis in cancer patients. Support Care Cancer. 2013; 21 (11): 3191-3207.

11. Morais TMN, Silva A, Avi ALR, Souza PHR, Knobel E, Camargo LFA. A importancia da atuacao odontológica em pacientes internados em unidade de terapia intensiva. Rev Bras Ter Intensiva [Internet]. 2006; 18 (4): 412-417. Disponible en: http://dx.doi.org/10.1590/ s0103-507x2006000400016

12. Elad S, Cheng KKF, Lalla RV, Yarom N, Hong C, Logan RM, et al. MASCC/ISOO clinical practice guidelines for the management of mucositis secondary to cancer therapy. Cancer. 2020; 126 (19): 4423-4431.

13. Silva AP, Caruso P, Jaguar GC, Carvalho PAG, Alves FA. Oral evaluation and procedures performed by dentists in patients admitted to the intensive care unit of a cancer center. Support Care Cancer. 2014; 22 (10): 2645-2650.

14. Saldanha KFD, Costa DC, Pinto SF, Gaetti Jardim EC. Avaliacao do índice de higiene oral do paciente crítico. Arch Health Invest [Internet]. 2016; 4 (6). Disponible en: https://www.archhealthinvestigation.com. br/ArcHI/article/view/1290

15. de Lacerda Vidal CF, Vidal AK, Monteiro JG Jr, Cavalcanti A, Henriques APC, Oliveira M, et al. Impact of oral hygiene involving toothbrushing versus chlorhexidine in the prevention of ventilatorassociated pneumonia: a randomized study. BMC Infect Dis. 2017; 17 (1): 112.

16. Halboub E, Al-Maweri SA, Alanazi RH, Qaid NM, Abdulrab S. Orofacial manifestations of COVID-19: a brief review of the published literature. Braz Oral Res. 2020; 34: e124.

17. Zecha JA, Raber-Durlacher JE, Nair RG, Epstein JB, Sonis ST, Elad S, et al. Low level laser therapy/photobiomodulation in the management of side effects of chemoradiation therapy in head and neck cancer: 
part 1: mechanisms of action, dosimetric, and safety considerations. Support Care Cancer. 2016; 24 (6): 2781-2792.

18. Goss LK, Coty M-B, Myers JA. A review of documented oral care practices in an intensive care unit. Clin Nurs Res. 2011; 20 (2): 181-196.

19. Franco JB, Ribas PF, Valente Júnior LAS, Matias DT, Varotto BLR, Hamza CR, et al. Hospital dentistry and dental care for patients with special needs: dental approach during COVID-19 pandemic. Braz Dent Sci. 2020; 23 (2): 1-9.

20. Feider LL, Mitchell P, Bridges E. Oral care practices for orally intubated critically ill adults. Am J Crit Care. 2010; 19 (2): 175-183.

21. Migliorati C, Hewson I, Lalla RV, Antunes HS, Estilo CL, Hodgson $\mathrm{B}$, et al. Systematic review of laser and other light therapy for the management of oral mucositis in cancer patients. Support Care Cancer. 2013; 21 (1): 333-341.

22. de Souza AF, Guimaraes AC, Ferreira EF. Evaluation of the implementation of new protocol of oral hygiene in an intensive care center for prevention of pneumonia associated with mechanical ventilation. REME. 2013; 17 (1): 178-192.

23. Gomes RFT, Castelo EF. Hospital dentistry and the occurrence of pneumonia. RGO [Internet]. 2019; 67. Disponible en: https://www. scielo.br/j/rgo/a/k4tC3d9RdX5fgydv7X6Lrwj/?lang=en

Correspondencia:

Luiz Fernando Lobo

E-mail:drlobo@drlobo.com.br 